\section{L'isolamento in emodialisi: una questione aperta}

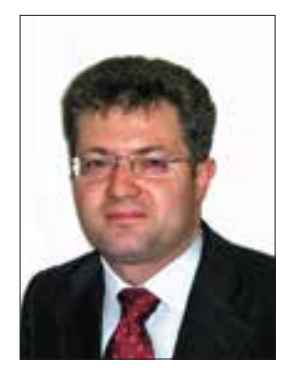

Gennaro Santorelli

\section{Gentilissimo Dottor Lombardi,}

Ho letto con grandissimo interesse la sua rassegna relativa all'utilizzo della contumaciale in dialisi per la prevenzione della diffusione delle infezioni da virus ematogeni.

Nel suo articolo si fa riferimento al fatto che il rispetto rigoroso delle precauzioni universali e speciali in sala dialisi rappresenta una condizione sufficiente atta a prevenire la diffusione delle infezioni da virus ematogeni; in particolare si sostiene, come già era stato evidenziato in un articolo da lei scritto nel 2009 (1), che in dialisi non è necessario l'isolamento dei pazienti $\mathrm{HbsAg}$ positivi e che non è necessario ricorrere alla contumaciale per ridurre o azzerare la diffusione del virus dell'epatite $B$.

I CDC (Centri di Controllo), d'altra parte, hanno sempre raccomandato l'isolamento dei pazienti HbsAg tramite l'utilizzo di sale contumaciali, macchinari dedicati e personale dedicato; inoltre la letteratura stessa fornisce diversi dati a favore di questa politica di isolamento.

Attualmente è evidente che questo argomento è estremamente dibattuto e di grande attualità; inoltre non si hanno certezze in merito e i dati epidemiologici a favore di una o dell'altra evidenza non sono tanti.

lo credo che, se consideriamo le 3 importanti caratteristiche del virus dell'epatite B:

1) ubiquità (è presente in tutti i liquidi biologici dell'organismo);

2) elevata resistenza nell'ambiente esterno (fino ad alcuni mesi) e a molti disinfettanti;

3) elevata carica virale (fino ad 1 miliardo di particelle/ml), ci si rende conto di quanto siano potenzialmente pericolosi i soggetti HbsAg positivi, soprattutto in un ambiente come la sala dialisi in cui vengono effettuate numerose manovre a rischio di diffusione ematogena.

D’altra parte la modalità di trasmissione del virus dell'epatite $B$ in dialisi è tendenzialmente di tipo parenterale inapparente, ovvero in grado di avvenire in presenza di microlesioni della cute del paziente suscettibile che venga a contatto col sangue di un paziente $\mathrm{HbsAg}$ positivo, di solito veicolato dai guanti degli infermieri. Bisogna considerare che nelle nostre sale vi è un'elevata concentrazione di pazienti e operatori e, sebbene le precauzioni universali e speciali siano molto precise nel raccomandare il cambio dei guanti per ogni manovra eseguita, riducendo poten- zialmente al minimo il rischio di veicolare il virus tramite il sangue, è stata dimostrata la presenza del virus stesso anche su forbici, clamp e comandi dei monitor di dialisi per diversi giorni.

Proprio per questi motivi, il mio parere è a favore dell'isolamento fisico dei pazienti $\mathrm{HbsAg}$ positivi da quelli negativi (non protetti da titolo anticorpale adeguato) con staff infermieristico dedicato. Anche l'utilizzo della macchina dedicata rappresenta un punto cruciale nella gestione dei soggetti $\mathrm{HbsAg}$ in dialisi; si è visto infatti che il rischio di trasmissione del virus per il contagio attraverso la macchina era a livello dei trasduttori di pressione, rappresentando quindi un punto critico nei confronti dei pazienti suscettibili.

Attualmente sappiamo che la vaccinazione per l'epatite B rappresenta una valida arma per combattere la diffusione del virus dell'epatite $B$, ma in realtà siamo consci del fatto che i pazienti in dialisi cronica vengono vaccinati poco perché:

1) è noto che il vaccino offre una risposta piuttosto bassa, con una frequenza di responders (responders: titolo anticorpale >10 UI/I) del 50\%;

2) alcuni ritengono che il vaccino non sia sicuro.

Un altro grosso problema legato alla vaccinazione dei pazienti è il decadimento nel tempo del titolo anticorpale, che spesso impone ulteriori cicli vaccinali per ripristinare un titolo anticorpale protettivo.

Alla luce di quanto detto, credo che non possiamo essere sicuri di proteggere completamente i pazienti $\mathrm{HbsAg}$ negativi non protetti se questi ultimi non vengono isolati fisicamente dai pazienti HbsAg positivi.

Per quanto riguarda il virus dell'epatite $C$, sono tante le ragioni che sconsigliano l'isolamento e l'utilizzo della macchina dedicata. La prima è più importante è legata alle caratteristiche del virus stesso, meno virulento e meno stabile del virus dell'epatite B; bisogna poi considerare che l'isolamento dovrebbe prevedere una ulteriore suddivisione in base ai diversi genotipi e sottotipi del virus, creando una pericolosa caduta di attenzione al di fuori dall'area della contumaciale. Inoltre non è possibile che il virus, per le sue dimensioni, superi il filtro e vada a infettare il paziente nella dialisi successiva (2).

In conclusione, ritengo estremamente necessaria l'attuazione delle precauzioni universali e speciali per la sala dialisi, ma credo sia ancora fondamentale mantenere l'isolamento con l'utilizzo della contumaciale e della macchina dedicata per i pazienti HbsAg positivi, in assenza di dati che ne evidenzino il contrario.

\section{Disclosures}

Financial support: No financial support was received for this submission. Conflict of interest: The author has no conflict of interest. 


\section{Gennaro Santorelli}

Divisione di Nefrologia e Dialisi, Ospedale di Desio, Desio (MB)

\section{Indirizzo per la corrispondenza:}

Dr. Gennaro Santorelli

Nefrologia e Dialisi

Ospedale di Desio

Via Mazzini 1

20832 Desio (MB)

gennaro.santorelli@aovimercate.org

\section{Bibliografia}

1. Lombardi M, Cherubini C. La mancata osservanza di tutte le precauzioni speciali è un reale rischio clinico in dialisi. G Ital Nefrol. 2009;25(5):625-31.

2. Fabrizi F, Martin P, Messa P. HCV, HBV, HIV ed emodialisi. G Ital Nefrol. 2013;30(4).

Published online: February 23, 2015 